\title{
Special Diet Therapy
}

National Cancer Institute

\section{Source}

National Cancer Institute. Special Diet Therapy. NCI Thesaurus. Code C15383.

A form of therapy which includes dietary approaches and special diets that are applied as alternative therapies for risk factors or chronic disease in general. 